\title{
EFFECT OF COLD PRESSOR TEST ON BLOOD PRESSURE IN SUBJECTS WITH HYPERTENSIVE FIRST DEGREE RELATIVES
}

\author{
Sandip R. Sardessai ${ }^{1}$, Sanjay S. Pandarbale ${ }^{2}$
}

1 Professor and HOD, Department of Physiology, Goa Medical College, Bambolim.

${ }^{2}$ Associate Professor, Department of Physiology, Goa Medical College, Bambolim.

\section{ABSTRACT}

\section{BACKGROUND}

Majority of individuals with essential hypertension and some with usually normal blood pressure manifest unusual lability and marked reaction of blood pressure to various internal and external stimuli. This suggests that mechanism for regulating blood pressure possessed by these individuals is hyperreactive.

The aim of the study was to find out effects of hand immersion in cold water (CPT) on blood pressure in subjects with their first-degree relatives who were hypertensive.

\section{MATERIALS AND METHODS}

For convenience, we took total of 300 apparently healthy medical students of both sexes in the age group of 18 to 22 years and comparative study was done in them. Amongst these 150 subjects had their first-degree relation hypertensive and served as experimental group, while remaining 150 did not have any family history of their first-degree relation hypertensive and served as controls. Subjects were asked to immerse their hand up to wrist in cold water (CPT) at $20^{\circ} \mathrm{C}$ and $10^{\circ} \mathrm{C}$ for a period of 30 seconds, during which their blood pressure was recorded.

\section{RESULTS}

Data was collected and was analysed using student's ' $t$ ' test and $p$ value of $<0.05$ was taken as scientifically significant. On hand immersion in cold water at $20^{\circ} \mathrm{C}$, both systolic and diastolic blood pressure was increased in both groups. In Control group the increase in systolic blood pressure was just significant compared with basal, while increase in diastolic blood pressure was not statistically significant. In experimental group, both increase in systolic and diastolic pressure was statistically significant compared with basal $(\mathrm{P}<0.01)$. Similarly, on hand immersion in cold water $(\mathrm{CPT})$ at $10^{\circ} \mathrm{C}$ the increase in systolic blood pressure was just significant in control group $(\mathrm{P}<0.05)$, while in experimental group it was highly significant $(\mathrm{P}<0.001)$.

\section{CONCLUSION}

Hand immersion in cold water (CPT) up to wrist at $20^{\circ} \mathrm{C}$ and $10^{\circ} \mathrm{C}$, there was increase in both systolic and diastolic blood pressure in both the groups.

\section{KEYWORDS}

Hypertensive First Degree Relatives, CPT, Hand Immersion in Water, $20^{\circ} \mathrm{C}$ and $10^{\circ} \mathrm{C}$, Systolic Blood Pressure, Diastolic Blood Pressure.

HOW TO CITE THIS ARTICLE: Sardessai SR, Pandarbale SS. Effect of cold pressor test on blood pressure in subjects with hypertensive first-degree relatives. J. Evolution Med. Dent. Sci. 2017;6(52):3963-3966, DOI: 10.14260/Jemds/2017/858

\section{BACKGROUND}

Temperature and many other stressors in the environment can affect BP in an individual. ${ }^{1}$ Hypertension (HTN) is a problem globally today. Arterial blood pressure is an important physiological parameter and has great significance in epidemiology of cardiovascular disease because of its association with age, sex, BMI, dietary habits, socioeconomic factors and stress. ${ }^{2}$ Essential HTN is the most common type, $88 \%$ among hypertensive people. We are also aware of complications associated with HTN like stroke, hypertensive retinopathy and nephropathy. ${ }^{3}$

Financial or Other, Competing Interest: None.

Submission 29-04-2017, Peer Review 17-06-2017,

Acceptance 23-06-2017, Published 29-06-2017.

Corresponding Author:

Dr. Sandip R. Sardessai,

Professor and HOD,

Department of Physiology,

Goa Medical College,

Bambolim-403202.

E-mail:dr.sandipsardessai@yahoo.com

DOI: $10.14260 /$ jemds/2017/858
Diastolic blood pressure shows less fluctuations in normal subjects and remains in limited range, so if diastolic blood pressure fluctuates then it is of great prognostic importance than that of systolic blood pressure.2,3

Majority of individuals with essential hypertension and some with usually normal blood pressure manifest unusual lability and marked reaction of blood pressure to various internal and external stimuli. CPT is non-invasive and simple test designed by Hines and Brown, which is used to identify an individual who is apparently healthy and normotensive but who is at risk of developing hypertension in later life. CPT is a standard stimulus to study vasomotor response in the individual. Systolic rise of blood pressure by $20 \mathrm{mmHg}$ and diastolic rise of blood pressure by $15 \mathrm{mmHg}$ is considered as normal response to test. ${ }^{4,5}$ If hypertension is detected in an individual, all the possible complications associated with HT can be controlled by practicing lifestyle modifications. Those individuals prone for hypertension and has predisposing factors following stress show higher and prolonged responsiveness of blood pressure. ${ }^{6}$ 
The present work was therefore undertaken to study the effects of hand immersion in cold water up to wrist on blood pressure in subjects with their first-degree relatives who are hypertensive.

\section{MATERIALS AND METHODS}

For convenience, we took 150 participants each and a total of 300 apparently healthy medical students of both sexes in the age group of 18 to 22 years and a comparative study was done in them; 150 participants were controls and 150 participants formed experimental group. The study participants were included after applying inclusion criteria of willingness to participate and readiness to give consent and those who had family history of first-degree relatives who were hypertensive. Both the groups were also screened for any history of taking alcohol, sedatives, regular exercise, martial arts, yoga, pranayama, meditation, COPD and those who did not have family history of their first-degree relatives who were hypertensive which are exclusion criteria. Amongst this 150 subjects who had their first-degree relatives who were hypertensive and served as experimental group, while remaining 150 who did not have family history of first-degree relatives who were hypertensive served as controls. The subjects came to the laboratory one-to-three hours postprandial and lay on the couch in supine position for 20 minutes. The nature of test was explained before its performance in order to minimise any apprehension on the part of the subject. Their basal (resting) blood pressure was measured using mercury sphygmomanometer. Methodology is as follows: Subjects were asked to immerse their right hand up to wrist in cold water at $20^{\circ} \mathrm{C}$ for 30 seconds, during which time their blood pressure was recorded from the left upper arm with a standard mercurial sphygmomanometer. Palpatory method was carried out before doing auscultatory method. Systolic blood pressure was recorded at the point when Korotkoff sound was first audible and diastolic blood pressure was recorded at the point when Korotkoff sound disappeared. Single reading was taken. Finally, after rest period of 10 minutes the same procedure was carried out using cold water at $10^{\circ} \mathrm{C}$. All the subjects were found to be having normal blood pressure, though the basal blood pressure (both systolic and diastolic) was insignificantly higher in experimental group. Data was collected and analysed using student's ' $t$ ' test and $p$ value of $<0.05$ was taken as statistically significant.

\section{RESULTS}

In our study, all the 300 subjects were found to have normal basal blood pressure, i.e. SBP ranged from $106 \mathrm{mmHg}$ to 124 $\mathrm{mmHg}$, while DBP ranged from $68 \mathrm{mmHg}$ to $82 \mathrm{mmHg}$. In case of controls, the basal mean SBP and DBP was $112 \mathrm{mmHg}$ and $74 \mathrm{mmHg}$ respectively. In the case of experimental group, the basal mean SBP and DBP was $115 \mathrm{mmHg}$ and $76 \mathrm{mmHg}$ respectively. However, this slightly higher basal systolic and diastolic blood pressure in experimental group compared with control was not statistically significant [Table I].

On hand immersion in cold water at $20^{\circ} \mathrm{C}$, both SBP and DBP was increased in both groups. In case of control group mean SBP increased from $112 \mathrm{mmHg}$ to $124 \mathrm{mmHg}$, while mean DBP pressure increased from $74 \mathrm{mmHg}$ to $80 \mathrm{mmHg}$. The increase in SBP was just significant compared with basal ( $\mathrm{P}<0.05$ ), while increase in DBP was not statistically significant. In experimental group, the mean SBP increased from $116 \mathrm{mmHg}$ to $138 \mathrm{mmHg}$, while mean DBP increased from $76 \mathrm{mmHg}$ to $90 \mathrm{mmHg}$. This increase in both SBP and DBP were statistically significant compared with basal values $(\mathrm{P}<0.01)$ [Table II, Graph 1].

On hand immersion in cold water at $10^{\circ} \mathrm{C}$ mean SBP increased up to $138 \mathrm{mmHg}$, while mean diastolic pressure increased up to $88 \mathrm{mmHg}$ in controls. This increase in both SBP and DBP were statistically significant compared with controls $(\mathrm{P}<0.01)$. In experimental group mean SBP increased to $146 \mathrm{mmHg}$, while mean DBP increased to 96 mmHg. This increase in both SBP and DBP were statistically highly significant compared with basal value $(\mathrm{P}<0.001)$ (Table III, Graph 2). In control group, 17 out of 150 subjects showed hyper reaction on hand immersion at $10^{\circ} \mathrm{C}$. The criteria for hyper reaction was the increase in SBP of more than $20 \mathrm{mmHg}$ and DBP more than $15 \mathrm{mmHg}$ from the basal values. However, if increase in DBP was more than $15 \mathrm{mmHg}$ without appreciable rise in SBP it was considered hyper reaction, since it is diastolic pressure which is more significant in pressor response of vascular reactivity. ${ }_{4}^{4}$ Taking individual subjects in experimental group 48 out of 100 subjects showed hyper reactivity to CPT, while remaining 17 did not show hyper reactivity to CPT.

\begin{tabular}{|c|c|c|}
\hline & SBP (mmHg) & DBP (mmHg) \\
\hline Control, $\mathrm{n}=150$ & $112 \pm 3$ & $74 \pm 1.8$ \\
\hline Experimental, $n=150$ & $115 \pm 3.5$ & $74 \pm 2$ \\
\hline P value & N.S & N.S \\
\hline \multicolumn{3}{|c|}{$\begin{array}{l}\text { Table I. Basal SBP and DBP of Control and Experimental } \\
\text { Group expressed as Mean } \pm \text { SEM }\end{array}$} \\
\hline
\end{tabular}

\begin{tabular}{|c|c|c|c|c|}
\hline & \multicolumn{2}{|c|}{ Control } & \multicolumn{2}{c|}{ Experimental } \\
\cline { 2 - 5 } & $\begin{array}{c}\text { SBP } \\
\text { (mmHg) }\end{array}$ & $\begin{array}{c}\text { DBP } \\
\text { (mmHg) }\end{array}$ & $\begin{array}{c}\text { SBP } \\
\text { (mmHg) }\end{array}$ & $\begin{array}{c}\text { DBP } \\
\text { (mmHg) }\end{array}$ \\
\hline $\begin{array}{c}\text { Basal BP } \\
\text { in mmHg }\end{array}$ & $112 \pm 3$ & $74 \pm 1.8$ & $115 \pm 3.5$ & $76 \pm 2$ \\
\hline $\begin{array}{c}\text { BP on Hand } \\
\text { Immersion in } \\
\text { Water at 20 }\end{array}$ & $124 \pm 5.2$ & $80 \pm 4$ & $138 \pm 7.4$ & $90 \pm 4.8$ \\
\hline P value & $<0.05^{*}$ & N.S & $<0.01^{* *}$ & $<0.01^{* *}$ \\
\hline
\end{tabular}

Table II. Effects of Hand Immersion in Cold Water at $20^{\circ} \mathrm{C}$ on SBP and DBP in Control and Experimental Group compared with Basal expressed as Mean \pm SEM

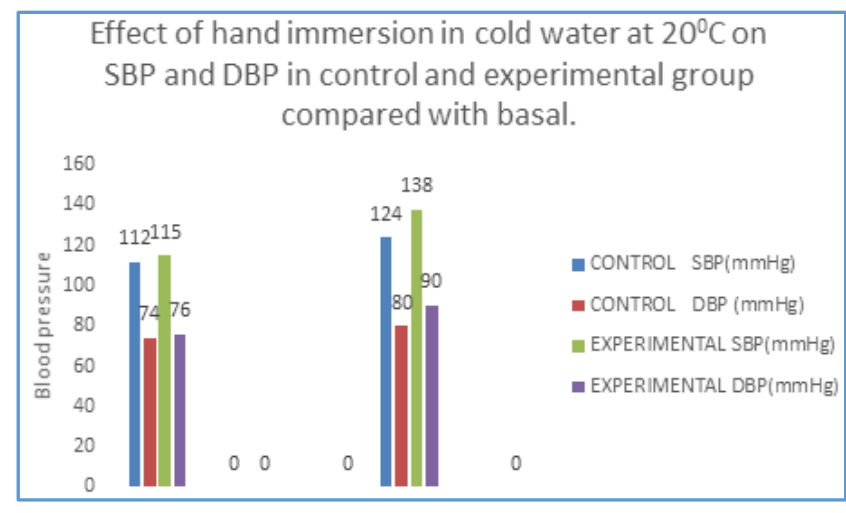

Graph 1 


\begin{tabular}{|c|c|c|c|c|}
\hline & \multicolumn{2}{|c|}{ Control } & \multicolumn{2}{c|}{ Experimental } \\
\hline & $\begin{array}{c}\text { SBP } \\
\text { (mmH) }\end{array}$ & $\begin{array}{c}\text { DBP } \\
\text { (mmHg) }\end{array}$ & $\begin{array}{c}\text { SBP } \\
\text { (mmHg) }\end{array}$ & $\begin{array}{c}\text { DBP } \\
\text { (mmH) }\end{array}$ \\
\hline $\begin{array}{c}\text { Basal BP } \\
\text { in mmHg }\end{array}$ & $112 \pm 3$ & $74 \pm 1.8$ & $115 \pm 3.5$ & $76 \pm 2$ \\
\hline $\begin{array}{c}\text { BP on Hand } \\
\text { Immersion in } \\
\text { Water at 10 } \mathrm{C}\end{array}$ & $124 \pm 5.2$ & $80 \pm 4$ & $138 \pm 7.4$ & $90 \pm 4.8$ \\
\hline P value & $<0.01^{* *}$ & $<0.01^{* *}$ & $<0.001^{* * *}$ & $<0.001^{* * *}$ \\
\hline
\end{tabular}

Table III. Effects of Hand Immersion in Water at $10^{\circ} \mathrm{C}$ on SBP and DBP in Control and Experimental Group compared with Basal expressed as Mean \pm SEM

Effect of hand immersion in cold water at $10^{\circ} \mathrm{C}$ on $\mathrm{SBP}$ and DBP in control and experimental group compared with basal.

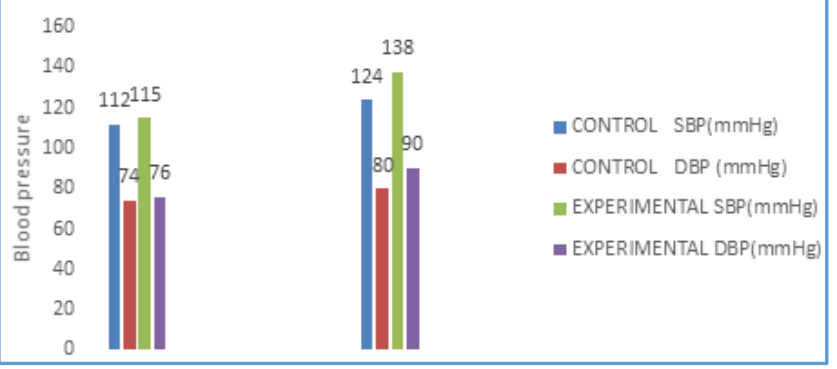

Graph 2

\section{DISCUSSION}

In our present study all the 300 subjects had normal basal blood pressure, though the basal blood pressure (both systolic and diastolic) was slightly higher in experimental group. This higher blood pressure could be due to genetic factors, as hypertension is known to run in families.2,3 However, this higher basal blood pressure in experimental group compared with controls was not statistically significant.

On hand immersion in cold water at $20^{\circ} \mathrm{C}$, both systolic and diastolic blood pressure was increased in both groups. Several studies in the past have proved that both chronic and acute exposure to cold leads to rise in blood pressure. CPT can act as a predictor of hypertension. ${ }^{5}$ CPT causes sympathetic activation and arteriolar vasoconstriction, which results in rise in BP. Sympathetic nervous system plays an important role in the pathogenesis of essential HT. Rise in BP is due to hyper-responsiveness to stress stimuli, which is due to sympathetic overactivity.6,7 Stimulation of sympathetic noradrenergic fibres causes vasoconstriction. The noradrenergic sympathetic nerves also contain NPY, which is a vasoconstrictor agent. This leads to increase in arteriolar blood pressure. Also impulses in the noradrenergic sympathetic nerves leads to increase in heart rate and force of contraction. ${ }^{3}$ In our study it was seen that on hand immersion in water at $20^{\circ} \mathrm{C}$ the rise in systolic pressure in controls was just significant compared with basal, while the rise in diastolic pressure was not statistically significant. On the other hand, in experimental group, both rise in systolic and diastolic pressures were statistically significant.

On hand immersion in water at $10^{\circ} \mathrm{C}$ the rise in systolic and diastolic pressures in control were statistically significant compared with basal $(\mathrm{P}<0.01)$, while the rise in systolic and diastolic pressure in experimental groups were highly significant compared with basal $(\mathrm{P}<0.001)$. The criteria for hyper reactors is when systolic pressure increases more than
$20 \mathrm{mmHg}$ it is called as systolic hyper reactors and when diastolic blood pressure increases more than $15 \mathrm{mmHg}$ it is called as diastolic hyper reactors. ${ }^{4}$ However, if the rise in diastolic pressure was greater than $15 \mathrm{mmHg}$ without appreciable rise in systolic pressure it was considered as hyper reaction, since it is diastolic pressure which is more significant in pressor response of vascular reaction. ${ }^{8}$ In our study, it was seen that in control group 17 out of 150 subjects showed hyper reaction on hand immersion at $10^{\circ} \mathrm{C}$. This means that those who have shown hyper reaction on hand immersion at $10^{\circ} \mathrm{C}$ are potential hypertensive and may develop hypertension at later age of life. Cold water at $20^{\circ}$ and $10^{\circ}$ can act as stressor. There is cold-induced pain which leads to increased activation of sympathetic nervous system and therefore there is increase in blood pressure. Studies done by Ritesh et al showed that CPT stress has its effect on blood pressure and those who had higher blood pressure after CPT are at risk of developing hypertension in later stage of life. ${ }^{9}$ Also studies have shown that increase in sympathetic activity in an individual leads to increase in cardiovascular reactivity. ${ }^{10}$ Studies done by Mahalakshmamma et al in the past have also found out that there are more number of hyper reactors to CPT in males as compared to females and CPT is a simple but still effective tool to monitor vascular reactivity in the individuals and development of hypertension in both genders in their later stage of life. ${ }^{11}$ Also studies done by various authors like Fahad et al, Mingzhi Zhang, Q Zhao and Mishra et al also showed that response to CPT can be used to study vascular disorder and hypertension in later stage of life. ${ }^{12,13,14,15}$ Also studies done by Marie-Helene Roy-Gagnon et al showed that response to blood pressure to CPT is heritable and genetic factors influence reactivity to blood pressure and recovery. 16

\section{Recommendations}

CPT being simple, non-invasive, cost-effective tool to find out systolic and diastolic blood group hyper reactors, we would recommend this test in all the adults so that before time we could identify the hyper reactors who would probably suffer from hypertension in later life, and complications of hypertension would be prevented by adopting healthy lifestyles.

\section{CONCLUSION}

Hand immersion in cold water (CPT) up to wrist at $20^{\circ} \mathrm{C}$ and $10^{\circ} \mathrm{C}$, there was increase in both systolic and diastolic blood pressure in both the groups.

In our study, it was seen that in control group 17 out of 150 subjects showed hyper reaction on hand immersion at $10^{\circ} \mathrm{C}$. This means that those who have shown hyper reaction on hand immersion at $10^{\circ} \mathrm{C}$ are potential hypertensive and may develop hypertension at later stage of life. CPT is a simple, non-invasive but still effective tool to monitor vascular hyper reactivity and development of hypertension in both genders in later stage of life.

\section{REFERENCES}

[1] Silverthorn DU, Michael J. Cold stress and cold pressor test. Advances in Physiology Education 2013; 37(1): 93-6. 
[2] Guyton AC, Hall JE. Blood pressure: Textbook of medical physiology. $10^{\text {th }}$ edn. Harcourt Brace and Company 2003:205-6.

[3] Ganong WF. Cardiovascular homeostasis in health disease. Review of medical physiology. $22^{\text {nd }}$ edn. New York: McGraw Hill 2005:631-46.

[4] Hines EA, Brown GE. The cold pressor test for measuring the reactibility of the blood pressure: data concerning 571 normal and hypertensive subjects. Am Heart J 1936; 11(1):1-9.

[5] Wood DL, Sheps SG, Elveback LR, et al. Cold pressor test as a predictor of hypertension. Hypertension 1984; 6(3):301-6.

[6] Pramanik T, Regmi P, Adhikari P, et al. Cold pressor test as predictor of hypertension. J The Univ Heart Ctr 2009; 4(3):177-80.

[7] Elfakharany AT, El Azab DR, Khaled SAA. Response to cold pressor test in normotensive adult females. Int J Adv Res Biol Sci 2016; 3(10):219-24.

[8] Srivastava RD, Kumar M, Shinghal R, et al. Influence of age and gender on cold pressor response in Indian population. Indian J of Physiol Pharmacol 2010; 54(2):174-8.

[9] Ritesh M, Karia MD, Mahavirsingh R, et al. Blood pressure response to cold pressor test in normal young healthy subjects: a prediction of future possibilities of hypertension. J Phys Pharm Adv 2012; 2(6):223-6.
[10] Verma V, Singh SK, Ghosh S. Identification of susceptibility to hypertension by the cold pressor test. Indian J Physiol Pharmacol 2005; 49(1):119-20.

[11] Vandavasi M, Sukumar CD. Gender variations in cardiovascular responses to cold pressor test in normal subjects. Sch J App Med Sci 2016; 4(8c): 2943-6.

[12] Ahad F, Ashfaq-ul-Hassan, Bhat TA, et al. Evaluation of physiological cardiovascular reactivity to cold pressor stress test. Asian Journal of Biomedical and Pharmaceutical Sciences 2015; 5(44):11-14.

[13] Zhang M, Zhao Q, Mills KT, et al. Factors associated with blood pressure response to the cold pressor test: the GenSalt study. American Journal of Hypertension 2013; 26 (9):1132-9.

[14] Zhao Q, Bazzano LA, Cao J, et al. Reproducibility of blood pressure response to the cold pressor test: the GenSalt study. Am J Epidemiol 2012; 176 (Suppl 7):S91-8.

[15] Mishra S, Manjareeka M, Mishra J. Blood pressure response to cold water immersion test. IJBPAS 2012; 1(10):1483-91.

[16] Roy-Gagnon MH, Weir MR, Sorkin JD, et al. Genetic influences on blood pressure response to the cold presssortest: results from HAPI Heart Study. J Hypertens 2008; 26(4):729-36. 